\title{
BMJ Open Association of the combination of weight gain after 20 years of age and current obesity with chronic kidney disease in Japan: a cross-sectional study
}

Hirotaka Ochiai, ${ }^{1}$ Takako Shirasawa, ${ }^{1}$ Takahiko Yoshimoto, ${ }^{1}$ Satsue Nagahama, ${ }^{\circledR}$ Mariko Kobayashi, ${ }^{2}$ Akira Minoura, ${ }^{1}$ Keiichiro Ikeda, ${ }^{1}$ Eri Ozaki, ${ }^{1}$ Hiromi Hoshino, ${ }^{1}$ Akatsuki Kokaze $^{1}$

To cite: Ochiai H, Shirasawa T, Yoshimoto T, et al. Association of the combination of weight gain after 20 years of age and current obesity with chronic kidney disease in Japan: a cross-sectional study. BMJ Open 2019;9:e027752. doi:10.1136/ bmjopen-2018-027752

- Prepublication history for this paper is available online. To view these files, please visit the journal online (http://dx.doi. org/10.1136/bmjopen-2018027752).

Received 6 November 2018 Revised 27 March 2019 Accepted 11 April 2019
Check for updates

(c) Author(s) (or their employer(s)) 2019. Re-use permitted under CC BY-NC. No commercial re-use. See rights and permissions. Published by BMJ.

${ }^{1}$ Department of Hygiene, Public Health and Preventive Medicine, Showa University School of Medicine, Shinagawa-ku, Tokyo, Japan

${ }^{2}$ Division of Occupational Health and Promotion, All Japan Labor Welfare Foundation, Shinagawaku, Tokyo, Japan

Correspondence to

Dr Hirotaka Ochiai;

h-ochiai@med.showa-u.ac.jp

\section{ABSTRACT}

Objectives Weight gain after 20 years of age is associated with chronic kidney disease (CKD). However, the impact of weight gain on CKD might differ by current obesity status. We investigated the association of the combination of weight gain after 20 years of age and current obesity with CKD among adults in Japan.

Design A cross-sectional study.

Setting and participants We analysed data from 94822 adults aged 40-64 years who had an annual health checkup in Japan from April 2013 to March 2014.

Primary outcome measure CKD was defined as an estimated glomerular filtration rate $<60 \mathrm{~mL} / \mathrm{min} / 1.73 \mathrm{~m}^{2}$ and/or proteinuria.

Results Both weight gain $\geq 10 \mathrm{~kg}$ after 20 years of age plus obesity (OR 2.21, 95\% $\mathrm{Cl} 2.07$ to 2.36 ) and weight gain of $\geq 10 \mathrm{~kg}$ plus non-obesity (OR $1.31,95 \% \mathrm{Cl} 1.21$ to 1.42) significantly increased the $\mathrm{OR}$ for CKD when compared with weight gain $<10 \mathrm{~kg}$ plus non-obesity in men. In women, weight gain $\geq 10 \mathrm{~kg}$ plus obesity (OR $2.04,95 \% \mathrm{Cl} 1.84$ to 2.25$)$ and weight gain $\geq 10 \mathrm{~kg}$ plus non-obesity (OR 1.53, 95\% Cl 1.36 to 1.72 ) significantly increased the OR for CKD compared with weight gain $<10 \mathrm{~kg}$ plus non-obesity. These results persisted even after adjustment for age, lifestyle factors, hypertension, dyslipidaemia and diabetes.

Conclusions Weight gain $\geq 10 \mathrm{~kg}$ after 20 years of age was significantly associated with CKD in both obese and non-obese subjects. Moreover, the influence of weight gain $\geq 10 \mathrm{~kg}$ plus obesity on CKD was greater than that of weight gain $\geq 10 \mathrm{~kg}$ plus non-obesity on CKD. The present study results suggest that it is important to consider weight gain after maturity in both obese and non-obese subjects to prevent CKD among Japanese middle-aged adults.

\section{INTRODUCTION}

Chronic kidney disease (CKD) is an independent risk factor for cardiovascular disease. ${ }^{1}$ In addition, CKD is a progressive disease associated with a continuous decrease in glomerular filtration rate, leading to end-stage renal disease $(\mathrm{ESRD}) .^{2} \mathrm{ESRD}$ is a serious health
Strengths and limitations of this study

The large sample size (>90000 participants).

- Obesity was defined by measured height and weight, which were more objective than self-reported values.

- Weight gain after 20 years of age was self-reported, which could limit the accuracy of weight gain measurements.

- This study design was cross-sectional, which cannot establish causal relationships.

outcome with both high economic and social costs, requiring dialysis or transplantation to sustain life. ${ }^{3}$ Thus, on a global basis, one can see that CKD is both a public health problem and a socioeconomic issue. ${ }^{4}$

The proportion of patients with CKD is higher in Japan than in other countries. ${ }^{5}$ In Japan in 2005, it was estimated that about 13.3 million people (approximately $13 \%$ of the adult population) had CKD. ${ }^{6}$ Moreover, Japan is one of the countries with the highest incidence of ESRD, and the number of Japanese patients with ESRD has increased over the past four decades. ${ }^{7}$ In addition, cardiovascular disease, anaemia and bone disease were reported to be complications of CKD. ${ }^{8}$ Therefore, it is very important to prevent CKD for the prevention of ESRD and CKD-related complications in Japan.

For the prevention of CKD, it is effective to focus on factors associated with this disease, and in particular, those factors that can be modified. A previous study showed that increases in body weight are associated with an increased risk for CKD. ${ }^{9}$ In addition, weight gain after 20 years of age is associated with CKD. ${ }^{10}$ However, the impact of weight gain on CKD might differ by current obesity status. Thus, it is important 
to examine the association between weight gain and CKD by considering current obesity status. We hypothesised that weight gain after 20 years of age is a risk factor for CKD regardless of current obesity status, and that people who had experienced weight gain after age 20 and are currently obese had higher risk for CKD than those who had experienced weight gain after age 20 but are currently not obese.

Accordingly, we investigated the association of the combination of weight gain after 20 years of age and current obesity with CKD among adults in Japan.

\section{METHODS}

\section{Subjects}

This was a cross-sectional study that used data from men and women aged 40-64 years old who had an annual health check-up conducted by the All Japan Labor Welfare Foundation, a health service centre in Japan, ${ }^{11}$ from 1 April 2013 to 31 March 2014. Subjects were mainly Japanese workers but included a small number of their dependents and foreign workers. Of 310577 subjects, 310498 participated in the present study. Of 310498 participants, serum creatinine levels were measured in 129910 . We excluded 35088 participants from the analysis due to missing data (body mass index (BMI): $n=103$, smoking status: $n=2612$, alcohol intake: $n=2627$, physical activity: $n=2874$, weight gain after 20 years of age: $n=2734$, systolic blood pressure: $n=21$, diastolic blood pressure: $n=21$, high-density lipoprotein cholesterol (HDL-C): $n=114$, low-density lipoprotein cholesterol (LDL-C): $\mathrm{n}=103$, triglycerides: $\mathrm{n}=114$, blood glucose level: $\mathrm{n}=29697$, haemoglobin A1c (HbA1c): $\mathrm{n}=2131$ and proteinuria: $\mathrm{n}=769$ ). Thus, 94822 participants were analysed (figure 1).

Written informed consent for use of the data in this study was obtained from all participants.

\section{Data collection}

A self-administered questionnaire, which was recommended for specific health examination by the Ministry of Health, Labour and Welfare, ${ }^{11}$ was used to assess weight gain after 20 years of age, smoking status, alcohol intake and physical activity. The questionnaire was completed at the annual health check-up. Information on weight gain after 20 years of age was obtained by the question 'Have you gained more than $10 \mathrm{~kg}$ after 20 years of age', ${ }^{10}$ and study subjects were asked to answer either yes or no.

Height and weight of each subject were measured to the nearest $0.1 \mathrm{~cm}$ and $0.1 \mathrm{~kg}$, respectively. The measurement was conducted by trained staff. BMI was calculated as weight $(\mathrm{kg})$ divided by squared height $(\mathrm{m})$. Blood pressure was measured in the sitting position using an automated machine (HEM-907, Omron, Kyoto, Japan).

A venous blood sample was collected, stored in a cooler at $4^{\circ} \mathrm{C}$ for transportation to an external laboratory (SRL, Tokyo, Japan), and HDL-C, LDL-C, triglycerides, blood

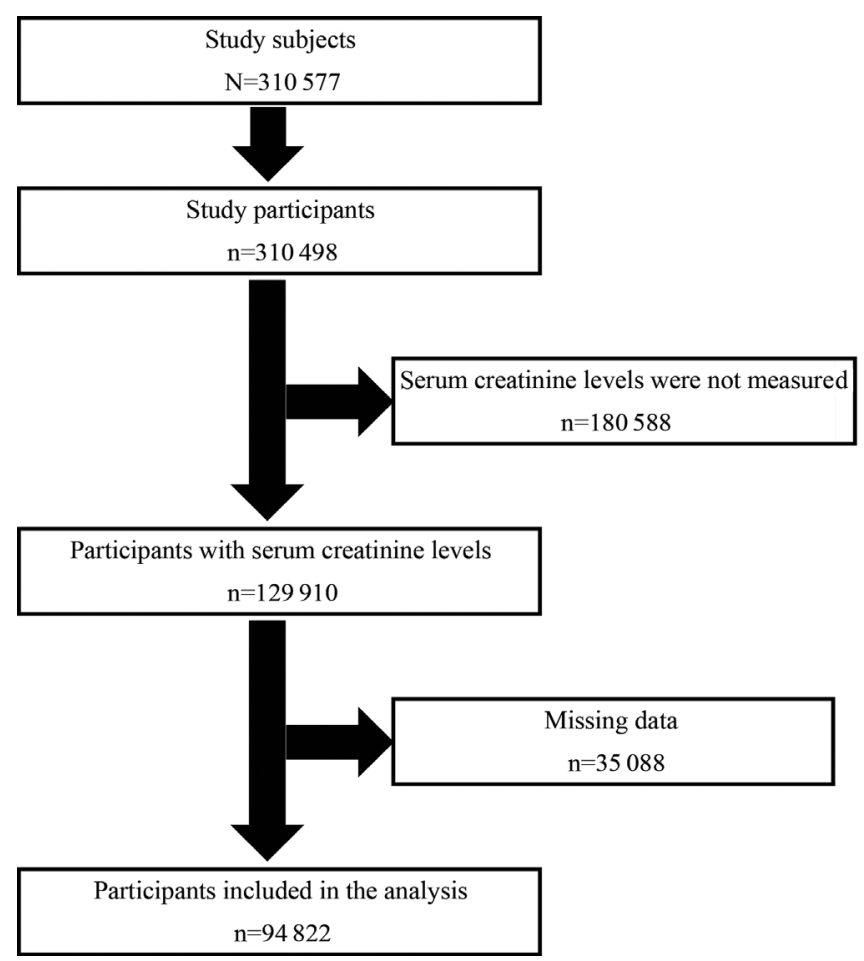

Figure 1 Flow diagram of study participants included in the analysis.

glucose, $\mathrm{HbAlc}$ and creatinine levels were measured within 24 hours of blood being drawn. HDL-C and LDL-C were determined by a direct method (AU5400, Beckman Coulter, Brea, California, USA), and triglyceride levels were measured by an enzyme method (AU5400, Beckman Coulter). Blood glucose levels were obtained using the hexokinase method (AU5400, Beckman Coulter), and HbAlc was measured by a latex agglutination method (JCA-BM9130, JEOL, Tokyo, Japan). Serum creatinine levels were determined by an enzyme method (AU5400, Beckman Coulter). The estimated glomerular filtration rate (eGFR) was calculated using the following formula: eGFR $=194 \times\left(\right.$ serum $\quad$ creatinine $\left.\mathrm{e}^{-1.094}\right) \times\left(\right.$ age $\left.^{-0.287}\right) \times(0.739$ for women). Urinary analysis was performed by dipstick testing. Urinary protein levels were measured as,, $- \pm 1+$, $2+$ or $3+$.

Hypertension was defined as systolic blood pressure $\geq 140 \mathrm{~mm} \mathrm{Hg}$, diastolic blood pressure $\geq 90 \mathrm{~mm} \mathrm{Hg}$, or taking medication for hypertension. ${ }^{112}$ Dyslipidaemia was defined as LDL-C $\geq 140 \mathrm{mg} / \mathrm{dL}$, HDL-C $<40 \mathrm{mg}$ / $\mathrm{dL}, \quad$ triglycerides $\geq 150 \mathrm{mg} / \mathrm{dL}$ or taking medication for dyslipidaemia. ${ }^{13}$ Diabetes was regarded as having a fasting plasma glucose ( $\geq 8$ hours after the last caloric intake $\left.{ }^{14}\right) \geq 126 \mathrm{mg} / \mathrm{dL}$, a random plasma glucose $\geq 200 \mathrm{mg} / \mathrm{dL}$, an HbA1c (National Glycohemoglobin Standardization Program) $\geq 6.5 \%$ or taking medication for diabetes. ${ }^{13}$

\section{Definition of obesity and CKD}

According toJapan Society for the Study of Obesity, obesity was defined as BMI $\geq 25 \mathrm{~kg} / \mathrm{m}^{2}{ }^{15}$ In accordance with 
Table 1 Characteristics of study participants by weight gain after 20 years of age in men

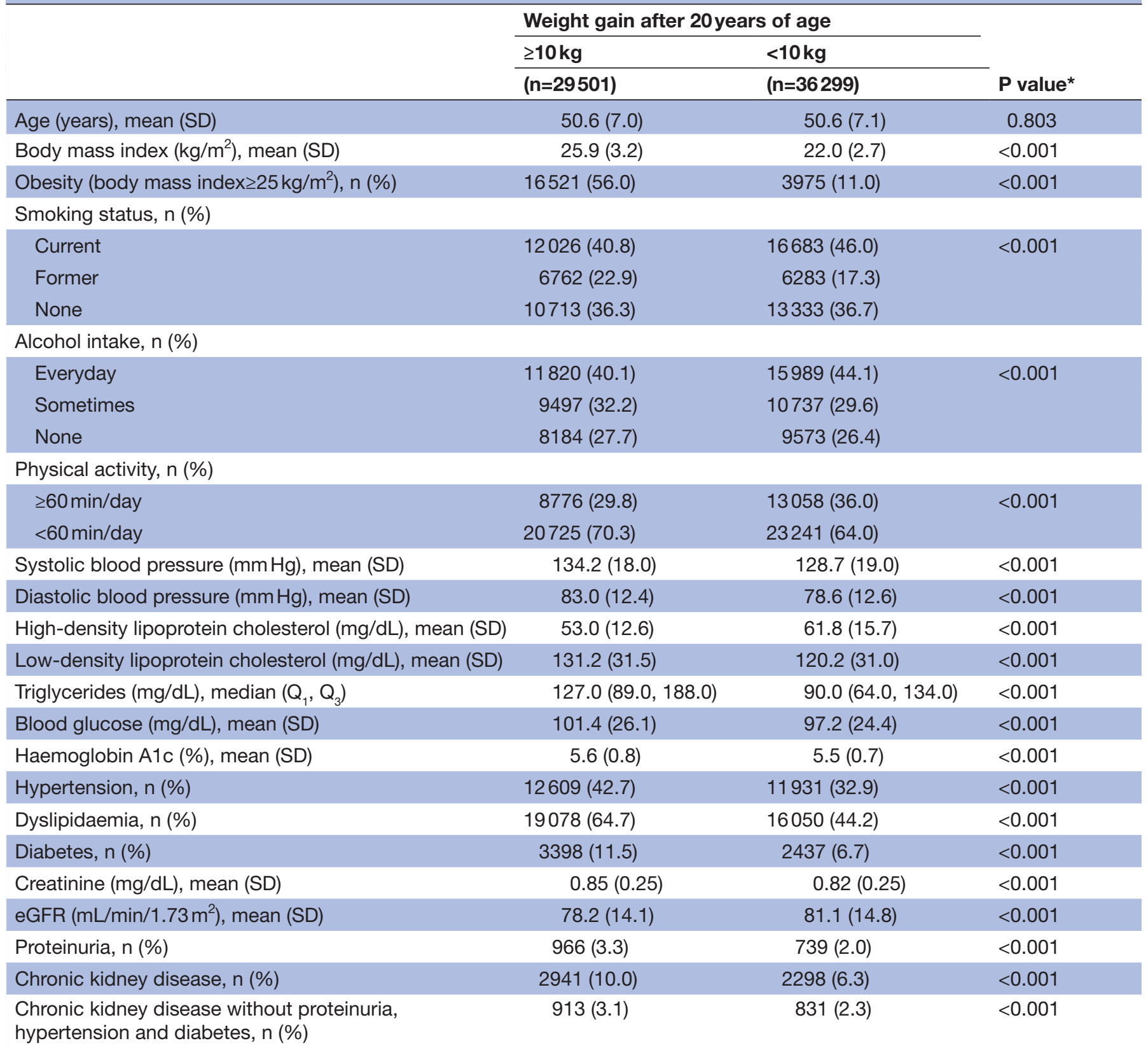

*Unpaired t-test, Wilcoxon's rank-sum test or chi-squared test.

eGFR, estimated glomerular filtration rate; $Q_{1}, 25$ th percentile; $Q_{3}, 75$ th percentile.

previous studies, ${ }^{16-18}$ CKD was defined as eGFR $<60 \mathrm{~mL} /$ $\min / 1.73 \mathrm{~m}^{2}$ and/or urinary protein of $1+, 2+$ or $3+$ (proteinuria).

\section{Statistical analyses}

Data are presented as mean (SD) for continuous variables and $\mathrm{n}(\%)$ for categorical variables. Because the distribution of data for triglyceride levels was highly skewed, data are shown as medians (25 percentile, 75 percentile). Unpaired t-test, Wilcoxon's rank sum test or chi-squared test was used to compare characteristics between the group with weight gain $\geq 10 \mathrm{~kg}$ after 20 years of age and the group with weight gain $<10 \mathrm{~kg}$ after 20 years of age. Logistic regression model was used to calculate the OR and 95\% CI for CKD. First, a crude OR was calculated in the first model. A second model controlled for potential confounding factors, including age, smoking status, alcohol intake, physical activity, hypertension, dyslipidaemia and diabetes. $^{10}$ 19-21 A cross-product interaction term included in the logistic regression model was used to assess the interaction.

A p value $<0.05$ was considered statistically significant. Statistical analyses were performed using SAS software V.9.4 (SAS Institute). 
Table 2 Characteristics of study participants by weight gain after 20 years of age in women

\begin{tabular}{|c|c|c|c|}
\hline & \multicolumn{2}{|c|}{ Weight gain after 20 years of age } & \multirow[b]{3}{*}{ P value* } \\
\hline & $\geq 10 \mathrm{~kg}$ & $<10 \mathrm{~kg}$ & \\
\hline & $(n=7873)$ & $(n=21149)$ & \\
\hline Age (years), mean (SD) & $51.0(6.9)$ & $50.5(6.9)$ & $<0.001$ \\
\hline Body mass index $\left(\mathrm{kg} / \mathrm{m}^{2}\right)$, mean (SD) & $26.0(3.7)$ & $20.9(2.6)$ & $<0.001$ \\
\hline Obesity (body mass index $\geq 25 \mathrm{~kg} / \mathrm{m}^{2}$ ), $\mathrm{n}(\%)$ & 4369 (55.5) & $1276(6.0)$ & $<0.001$ \\
\hline \multicolumn{4}{|l|}{ Smoking status, $\mathrm{n}(\%)$} \\
\hline Current & $1502(19.1)$ & $3885(18.4)$ & \multirow[t]{3}{*}{$<0.001$} \\
\hline Former & $736(9.4)$ & $1357(6.4)$ & \\
\hline None & $5635(71.6)$ & $15907(75.2)$ & \\
\hline \multicolumn{4}{|l|}{ Alcohol intake, n (\%) } \\
\hline Everyday & $1160(14.7)$ & $3589(17.0)$ & \multirow[t]{3}{*}{$<0.001$} \\
\hline Sometimes & $2358(30.0)$ & $6318(29.9)$ & \\
\hline None & $4355(55.3)$ & $11242(53.2)$ & \\
\hline \multicolumn{4}{|l|}{ Physical activity, n (\%) } \\
\hline$\geq 60 \mathrm{~min} /$ day & $2215(28.1)$ & $6498(30.7)$ & \multirow[t]{2}{*}{$<0.001$} \\
\hline$<60 \mathrm{~min} /$ day & $5658(71.9)$ & $14651(69.3)$ & \\
\hline Systolic blood pressure (mm Hg), mean (SD) & $130.9(20.7)$ & $121.2(19.6)$ & $<0.001$ \\
\hline Diastolic blood pressure (mm Hg), mean (SD) & $79.2(13.0)$ & $73.1(12.2)$ & $<0.001$ \\
\hline High-density lipoprotein cholesterol (mg/dL), mean (SD) & $61.2(14.3)$ & $71.4(15.9)$ & $<0.001$ \\
\hline Low-density lipoprotein cholesterol (mg/dL), mean (SD) & $133.1(32.2)$ & $121.0(30.6)$ & $<0.001$ \\
\hline Triglycerides $(\mathrm{mg} / \mathrm{dL})$, median $\left(\mathrm{Q}_{1}, \mathrm{Q}_{3}\right)$ & $97.0(68.0,140.0)$ & $68.0(51.0,95.0)$ & $<0.001$ \\
\hline Blood glucose (mg/dL), mean (SD) & $96.9(21.9)$ & $90.8(15.8)$ & $<0.001$ \\
\hline Haemoglobin A1c (\%), mean (SD) & $5.6(0.7)$ & $5.4(0.5)$ & $<0.001$ \\
\hline Hypertension, n (\%) & $3101(39.4)$ & $5495(26.0)$ & $<0.001$ \\
\hline Dyslipidaemia, n (\%) & $4313(54.8)$ & $7807(36.9)$ & $<0.001$ \\
\hline Diabetes, n (\%) & $618(7.9)$ & $452(2.1)$ & $<0.001$ \\
\hline Creatinine (mg/dL), mean (SD) & $0.65(0.16)$ & $0.63(0.13)$ & $<0.001$ \\
\hline eGFR $\left(\mathrm{mL} / \mathrm{min} / 1.73 \mathrm{~m}^{2}\right)$, mean (SD) & $78.0(15.6)$ & $79.6(14.4)$ & $<0.001$ \\
\hline Proteinuria, $\mathrm{n}(\%)$ & $144(1.8)$ & $228(1.1)$ & $<0.001$ \\
\hline Chronic kidney disease, $\mathrm{n}(\%)$ & $1010(12.8)$ & $1656(7.8)$ & $<0.001$ \\
\hline $\begin{array}{l}\text { Chronic kidney disease without proteinuria, hypertension } \\
\text { and diabetes, } \mathrm{n}(\%)\end{array}$ & $448(5.7)$ & $964(4.6)$ & $<0.001$ \\
\hline
\end{tabular}

*Unpaired t-test, Wilcoxon's rank-sum test or chi-squared test.

eGFR, estimated glomerular filtration rate; $Q_{1}, 25$ th percentile; $Q_{3}, 75$ th percentile.

\section{Patient and public involvement statement}

No patient was involved in the design and conception of the study.

\section{RESULTS}

Tables 1 and 2 show characteristics of study participants by weight gain after 20 years. The proportions of obesity, hypertension, dyslipidaemia, diabetes and proteinuria were significantly higher in participants with weight gain $\geq 10 \mathrm{~kg}$ after 20 years of age than in those without this weight gain. In addition, BMI, systolic blood pressure, diastolic blood pressure, LDL-C, triglycerides, blood glucose, HbAlc and creatinine levels were significantly higher in participants with weight gain $\geq 10 \mathrm{~kg}$ after 20 years of age than in those without this weight gain. In contrast, HDL-C and eGFR levels were significantly lower in participants with weight gain $\geq 10 \mathrm{~kg}$ after 20 years of age than in those without this weight gain. There were statistically significant differences in lifestyle factors (smoking status, alcohol intake and physical activity) between participants with and without weight gain $\geq 10 \mathrm{~kg}$ since 20 years of age. The proportion of CKD in participants with weight gain $\geq 10 \mathrm{~kg}$ after 20 years of age was significantly higher than that in those without the weight 
Table 3 Association between 'the combination of weight gain of $\geq 10 \mathrm{~kg}$ after 20 years of age and obesity' and CKD by sex

\begin{tabular}{|c|c|c|c|c|}
\hline & Total & CKD & Crude & Adjusted \\
\hline & $\mathbf{N}$ & n (\%) & OR $(95 \% \mathrm{Cl})$ & OR $(95 \% \mathrm{Cl})$ \\
\hline \multicolumn{5}{|l|}{ Men } \\
\hline Weight gain of $\geq 10 \mathrm{~kg}$ and non-obesity & 12980 & $967(7.5)$ & 1.31 (1.21 to 1.42$)$ & $1.22(1.13$ to 1.33$)$ \\
\hline Weight gain of $<10 \mathrm{~kg}$ and obesity & 3975 & $428(10.8)$ & 1.97 (1.76 to 2.20$)$ & 1.79 (1.60 to 2.01$)$ \\
\hline \multicolumn{5}{|l|}{ Women } \\
\hline Weight gain of $\geq 10 \mathrm{~kg}$ and obesity & 4369 & $622(14.2)$ & 2.04 (1.84 to 2.25$)$ & 1.89 (1.70 to 2.10$)$ \\
\hline Weight gain of $\geq 10 \mathrm{~kg}$ and non-obesity & 3504 & $388(11.1)$ & 1.53 (1.36 to 1.72$)$ & 1.43 (1.27 to 1.61$)$ \\
\hline Weight gain of $<10 \mathrm{~kg}$ and obesity & 1276 & $157(12.3)$ & 1.72 (1.44 to 2.05$)$ & 1.66 (1.39 to 1.98$)$ \\
\hline Weight gain of $<10 \mathrm{~kg}$ and non-obesity & 19873 & $1499(7.5)$ & 1.00 & 1.00 \\
\hline
\end{tabular}

Adjusted for age, smoking status, alcohol intake, physical activity, hypertension, dyslipidaemia and diabetes.

CKD, chronic kidney disease.

gain. The proportion of participants with CKD without proteinuria, hypertension and diabetes was significantly higher in participants with weight gain $\geq 10 \mathrm{~kg}$ after 20 years of age than in those without this weight gain.

Table 3 shows the association between 'the combination of weight gain $\geq 10 \mathrm{~kg}$ after 20 years of age and obesity' and CKD by sex. In men, weight gain $\geq 10 \mathrm{~kg}$ after 20 years of age plus obesity significantly increased the OR for CKD (OR 2.21, 95\% CI 2.07 to 2.36) compared with weight gain $<10 \mathrm{~kg}$ plus non-obesity. Significantly increased ORs were also observed in weight gain $\geq 10 \mathrm{~kg}$ plus non-obesity (OR 1.31, 95\% CI 1.21 to 1.42 ) and weight gain $<10 \mathrm{~kg}$ plus obesity (OR $1.97,95 \%$ CI 1.76 to 2.20). Similar results were found in women, that is, weight gain $\geq 10 \mathrm{~kg}$ plus obesity (OR $2.04,95 \%$ CI 1.84 to 2.25 ), weight gain $\geq 10 \mathrm{~kg}$ plus non-obesity (OR $1.53,95 \%$ CI 1.36 to 1.72 ) and weight gain $<10 \mathrm{~kg}$ plus obesity (OR 1.72 , $95 \%$ CI 1.44 to 2.05 ) significantly increased the OR for CKD compared with weight gain $<10 \mathrm{~kg}$ plus non-obesity. These results persisted even after adjustment for age, lifestyle factors, hypertension, dyslipidaemia and diabetes. The proportion of participants with CKD without proteinuria, hypertension and diabetes was significantly higher in participants with weight gain $\geq 10 \mathrm{~kg}$ after 20 years of age than in those without this weight gain. The interaction of weight gain $\geq 10 \mathrm{~kg}$ after 20 years of age and obesity on CKD was statistically significant in men ( $p$ value $=0.028$ ) and in women ( $\mathrm{p}$ value $=0.024)$.

\section{DISCUSSION}

\section{Summary findings}

The present study investigated the association of the combination of weight gain $\geq 10 \mathrm{~kg}$ after 20 years of age and current obesity with CKD. Results showed that weight gain $\geq 10 \mathrm{~kg}$ after 20 years of age was significantly associated with CKD regardless of current obesity status. To our knowledge, this is the first study examining the association between 'the combination of weight gain after 20 years of age and obesity' and CKD.

\section{Association of the combination of weight gain after 20 years of age and current obesity with CKD}

In our study, weight gain after 20 years of age was significantly associated with CKD regardless of current obesity status. A previous study showed that increases in body weight were associated with an increased risk for CKD, even when the BMI remained within the normal range. ${ }^{9}$ The results suggest that it is important to consider weight gain in adults for the prevention of CKD in both obese and non-obese subjects. Therefore, it might be necessary to monitor current obesity status as well as weight gain after 20 years of age to prevent CKD.

The reason weight gain after 20 years of age was associated with CKD might be due to an increased fat mass. A recent study showed that weight gain after maturity largely reflects an increase in fat mass. ${ }^{10}$ In addition, weight gain from early adulthood can be attributed mainly to the accumulation of adipocytes. ${ }^{22}$ Moreover, adipose tissue has been shown to be associated with insulin resistance, which is a key metabolic risk promoting CKD. ${ }^{23}$ Therefore, it is possible that weight gain after 20 years of age shows an increase in fat mass and the fat gain contributes to insulin resistance, resulting in the increased risk for CKD.

Although weight gain $\geq 10 \mathrm{~kg}$ after 20 years of age plus obesity and weight gain $\geq 10 \mathrm{~kg}$ after 20 years of age plus non-obesity were significantly associated with CKD, the influence of the weight gain plus obesity on CKD was greater than that of the weight gain plus non-obesity on CKD. In this study, the interaction of weight gain $\geq 10 \mathrm{~kg}$ after 20 years of age and obesity on CKD was statistically significant, suggesting that the combination of these factors may have a substantial impact on CKD. Weight gain during adulthood was reported to be associated with 
CKD. ${ }^{9}{ }^{10}$ Moreover, Gelber et al reported that compared with those who remained within $\pm 5 \%$ of their baseline BMI, those who reported a BMI increase $>10 \%$ had a significant increase in risk for $\mathrm{CKD} .{ }^{19}$ In addition, a recent study reported that obesity was associated with CKD. ${ }^{24}$ Thus, there might be a synergistic impact of weight gain and obesity on CKD. Further studies are needed to elucidate the biological mechanism of this impact.

\section{Other implications}

In this study, $2.7 \%$ in men and $4.9 \%$ in women had CKD without proteinuria, hypertension and diabetes. In addition, the proportion of participants with CKD without proteinuria, hypertension and diabetes was higher in participants with weight gain $\geq 10 \mathrm{~kg}$ after 20 years of age than in those without this weight gain. In Japan, the measurement of serum creatinine levels was not mandatory. Thus, our study findings suggest that it is necessary to measure serum creatinine levels among all middleaged adults, especially those with weight gain $\geq 10 \mathrm{~kg}$ after 20 years of age, for the early detection of CKD.

\section{Strengths and limitations}

The strength of the present study is the large sample size ( $>90000$ participants), which contributes to the decrease in random error. Moreover, height and weight of study participants were measured by trained technicians, and these values were used to determine obesity in this study. However, our study has some limitations. First, weight gain in the present study was self-reported. However, it is possible that the influence of self-reported weight gain on the present results was not substantial, as the validity of recall of past body weight has been measured in several studies and tends to be high in young and middle-aged adults. ${ }^{25}$ Second, not all potential confounding factors were obtained in our study, which might affect findings. For instance, family history of CKD is reported to be associated with CKD. ${ }^{20}$ Therefore, the possibility of residual confounding was not addressed. Third, serum creatinine levels were measured in 129910 of 310498 participants in this study. The reason might be that the measurement of serum creatinine levels was not mandatory in Japan. Comparisons of characteristics between participants with and without serum creatinine levels showed that those with serum creatinine levels tended to be younger and to have a lower proportion of proteinuria than those without serum creatinine levels. These results could limit the generalizability of the present study findings to other populations. Finally, this study design was cross-sectional, which means that no causal relationship can be established. Further cohort studies are needed to establish causality.

\section{CONCLUSIONS}

Weight gain $\geq 10 \mathrm{~kg}$ after 20 years of age was significantly associated with CKD in both obese and non-obese subjects. Furthermore, the influence of the combination of weight gain $\geq 10 \mathrm{~kg}$ after age 20 plus obesity on CKD was greater than that of the weight gain plus non-obesity. The present study results suggest that it is important to consider weight gain after maturity in both obese and non-obese subjects to prevent CKD among Japanese middle-aged adults.

Acknowledgements The authors thank Dr Nobuo Yanagisawa, Dr Takeshi Kawaguchi, Mr Takahiro Tamura and Mr Yutaka Hoshina in the All Japan Labor Welfare Foundation for their support.

Contributors HO, TS and TY planned this study and interpreted the data. HO conducted the statistical analysis and drafted the manuscript. SN and MK contributed to the acquisition of data and helped draft the manuscript. AM, KI and $\mathrm{EO}$ contributed to improving the study in a meaningful way. $\mathrm{HH}$ supported the statistical analysis and the draft of the manuscript. AK made substantial contributions to the conception of the study and the revision of the manuscript. All authors have read and approved the final manuscript.

Funding The authors have not declared a specific grant for this research from any funding agency in the public, commercial or not-for-profit sectors.

Competing interests None declared.

Patient consent for publication Not required.

Ethics approval The Medical Ethics Committee of Showa University School of Medicine (Approval No. 2133) and the Ethics Committee of the All Japan Labor Welfare Foundation (Approval No. 2-1-0003) approved this study.

Provenance and peer review Not commissioned; externally peer reviewed.

Data sharing statement № additional data are available.

Open access This is an open access article distributed in accordance with the Creative Commons Attribution Non Commercial (CC BY-NC 4.0) license, which permits others to distribute, remix, adapt, build upon this work non-commercially, and license their derivative works on different terms, provided the original work is properly cited, appropriate credit is given, any changes made indicated, and the use is non-commercial. See: http://creativecommons.org/licenses/by-nc/4.0/.

\section{REFERENCES}

1. Ninomiya T, Kiyohara Y, Kubo M, et al. Chronic kidney disease and cardiovascular disease in a general Japanese population: the Hisayama Study. Kidney Int 2005;68:228-36.

2. Sharaf El Din UA, Salem MM, Abdulazim DO. Stop chronic kidney disease progression: Time is approaching. World $\mathrm{J}$ Nephrol 2016;5:258-73.

3. de Moura L, Prestes IV, Duncan BB, et al. Dialysis for end stage renal disease financed through the Brazilian National Health System, 2000 to 2012. BMC Nephrol 2014;15:111.

4. Yamagata K, Yagisawa T, Nakai S, et al. Prevalence and incidence of chronic kidney disease stage G5 in Japan. Clin Exp Nephrol 2015;19:54-64.

5. Inaguma D, Imai E, Takeuchi A, et al. Risk factors for CKD progression in Japanese patients: findings from the Chronic Kidney Disease Japan Cohort (CKD-JAC) study. Clin Exp Nephrol 2017;21:446-56.

6. Imai E, Horio M, Watanabe T, et al. Prevalence of chronic kidney disease in the Japanese general population. Clin Exp Nephrol 2009;13:621-30.

7. Tanaka K, Watanabe T, Takeuchi A, et al. Cardiovascular events and death in Japanese patients with chronic kidney disease. Kidney Int 2017;91:227-34.

8. Webster AC, Nagler EV, Morton RL, et al. Chronic Kidney Disease. Lancet 2017;389:1238-52.

9. Ryu S, Chang Y, Woo HY, et al. Changes in body weight predict CKD in healthy men. J Am Soc Nephrol 2008;19:1798-805.

10. Wakasugi M, Narita I, Iseki K, et al. Weight gain after 20 years of age is associated with prevalence of chronic kidney disease. Clin Exp Nephrol 2012;16:259-68.

11. Nagahama S, Kurotani K, Pham NM, et al. Self-reported eating rate and metabolic syndrome in Japanese people: cross-sectional study. BMJ Open 2014;4:e005241.

12. Foster MC, Hwang SJ, Larson MG, et al. Overweight, obesity, and the development of stage 3 CKD: the Framingham Heart Study. Am J Kidney Dis 2008;52:39-48. 
13. Nanri A, Nakagawa T, Kuwahara K, et al. Development of Risk Score for Predicting 3-Year Incidence of Type 2 Diabetes: Japan Epidemiology Collaboration on Occupational Health Study. PLOS One 2015;10:e0142779.

14. Kabeya $Y$, Kato $M$, Isogawa $A$, et al. Descriptive epidemiology of diabetes prevalence and $\mathrm{HbA} 1 \mathrm{c}$ distributions based on a selfreported questionnaire and a health checkup in the JPHC diabetes study. J Epidemiol 2014;24:460-8.

15. Examination Committee of Criteria for 'Obesity Disease' in JapanJapan Society for the Study of Obesity. New criteria for 'obesity disease' in Japan. Circ $J$ 2002;66:987-92.

16. $\mathrm{He} \mathrm{Y,} \mathrm{Li} \mathrm{F,} \mathrm{Wang} \mathrm{F,} \mathrm{et} \mathrm{al.} \mathrm{The} \mathrm{association} \mathrm{of} \mathrm{chronic} \mathrm{kidney} \mathrm{disease}$ and waist circumference and waist-to-height ratio in Chinese urban adults. Medicine 2016;95:e3769.

17. Nakamura $\mathrm{K}$, Nakagawa $\mathrm{H}$, Murakami $\mathrm{Y}$, et al. Smoking increases the risk of all-cause and cardiovascular mortality in patients with chronic kidney disease. Kidney Int 2015;88:1144-52.

18. Ohno $\mathrm{Y}$, Ishimura $\mathrm{E}$, Naganuma $\mathrm{T}$, et al. Prevalence of and factors associated with chronic kidney disease (CKD) in Japanese subjects without notable chronic diseases, undergoing an annual health checkup. Kidney Blood Press Res 2012;36:139-48.
19. Gelber RP, Kurth T, Kausz AT, et al. Association between body mass index and CKD in apparently healthy men. Am J Kidney Dis 2005;46:871-80.

20. Kazancioğlu R. Risk factors for chronic kidney disease: an update. Kidney Int Suppl 2013;3:368-71.

21. Salinero-Fort MA, San Andrés-Rebollo FJ, de Burgos-Lunar C, et al. Five-year incidence of chronic kidney disease (stage 3-5) and associated risk factors in a Spanish cohort: the MADIABETES Study. PLoS One 2015;10:e0122030.

22. Sogabe N, Sawada SS, Lee IM, et al. Weight change after 20 years of age and the incidence of dyslipidemia: a cohort study of Japanese male workers. J Public Health 2016;38:e77-83.

23. Declèves AE, Sharma K. Obesity and kidney disease: differential effects of obesity on adipose tissue and kidney inflammation and fibrosis. Curr Opin Nephrol Hypertens 2015;24:28-36.

24. Snyder S, Turner GA, Turner A. Obesity-related Kidney Disease. Prim Care 2014;41:875-93.

25. Kyulo NL, Knutsen SF, Tonstad S, et al. Validation of recall of body weight over a 26-year period in cohort members of the Adventist Health Study 2. Ann Epidemiol 2012;22:744-6. 